
orange, will nearly do. If these two last be made to partially
overlap the effect is very striking.

Swansea, May 6

\section{The Araucaria}

In your first number for March last you express your surprise that we should still be ignorant regarding some important phases of salmon life; but there is a question relating to facts much more within the sphere of our daily observation on which authorities differ as much. Does the common Araucaria $(A$. imbricata) require one year or two for the growth of a shoot on the main stem, estimating a shoot as the growth between two whorls of branches? Every gardener whom I have consulted on the subject in Scotland, from north to south, says positively that it requires two years, while the few of whom $I$ have had any opportunity of inquiring in the south of England, decide equally positively in favour of one year. Prof. Balfour agrees with the former in as far as Scotland is concerned, while a gentleman residing on the border between the two countries, informs me that some of his have grown at the rate of a shoot in two years, others of a shoot annually, while a few show only a shoot for every year and a half since they were planted. It has been suggested to me that the difference, if it really exist, may be clue to the more favourable climate of Enrland; but arautcarias may be seen growing as freely and as healthily in Ross-shire as in Kew Gardens, It would be satisfactory to have more general information on the subject from England and from the Continent of Europe, and still better to have it from the native countries of the tree.

There is another question equally important regarding it, namely, when the shouts are biennial, as they undoubtedly are in many cases, is there a timber ring in the stem for every year's growth, or one for every whorl of branches? On that point also the evidence is cuntradictory.

JAMES ElLiO'T

\section{The Hibernaticn of Swallows}

IN connection with the Duke of Argyll's letter on this subject (NATURE, vol. xv. p. 527) there is an interesting communication in the Ornithologisches Centralblatt of May I from Herr J. Rohweder, under the head of "Ornithological Notes from Schleswig-Holstein." Herr Rohweder certifies to the competency and trustworthiness of the observer who communicated the facts to him. After the house-swallows (Hirutdo urbica) in the autumn of 1870 , from the beginning to the middle of September, had held their usual assemblies by hundreds on the sunny side of the roofs, stormy and rainy cold weather suddenly supervened. As suddenly did most of the swallows take their departure for the south. 'The few that remained behind flew about restlessly and anxiously, unable in the cold north wind to obtain sufficient insects to appease their hunger. Within a day after the others these also disappeared. Three days after, during which time no swallow was observed, Herr Rohweder's informant saw peeping out of the entrance of some nests under the projecting roof of the east side of his house, here a wing, there a tail or a few feathers. A ladder was obtained and the nests tapped, but no motion. On pulling at one of the overhanging wings swallow was dragged out. It was alive, but seemed paralysed. After the swallow was held in the hand a while it fluttered about a short space and then fell to the earth. A second bird behaved in the same way, and a third showed few signs of life. A fourth appeared quite lifeless. In other nests six, and ten, and even fourteen swallows were found huddled together. Their condition was similar to those first found. The birds near the entrance of the nest appeared in a state of sound sleep, while those furthe in showed no signs of life. The former soon were able to fly, with difficulty, a larger or shorter round, only one flying to a considerable distance ; the latter were thrown on a neighbouring heap of straw. On the following day, when the observer re. turned, no birds were found. The exact locality of these observations is not given.

$\mathrm{X}$.

\section{Two Remarkable Meteors}

WHILST walking on Sunday night with a friend, about 10:35 my attention was directed to a beautiful meteor, of a ruddy hue, not unlike Mars. It appeared a little to the south of Arcturus, and after passing along with a slow motion in an easterly direction, throwing out sparks meanwhile, disappeared near $\beta$ Herculis. In size it seemed to be about four times as large as Jupiter, and continued visible for three or four seconds. About half a minute afterwards it was followed by another from the same quarter, which took almost exactly the same direction as the other. In colour and appearance it resembled the first, but was not quite so large. It remained visible about three seconds. The sky at the time was beautifully clear, and there was inttle or no wind.

Rottingdean, Brighton, May I4

W. I. S. J. MOPE

\section{Yellow Crocuses}

(Translation)

I lave observed here that sparrows have shown a very considerable partiality for $y$ sllow crocuses during this spring. My neighbour and I vied with each other in our spring beds; he excelled in yellow crocuses and hyacinths, I in white and blue crocuses. One beautiful Sunday the whole of his crocuses were found bitten and torn by sparrows, and, what is noteworthy, also some yellow crocuses which had somehow wandered into my lot, while the blue and white remained almost untouched. Should this be regarded as an oversight, or was it a matter of taste?

So far the fact is incontestable, but it has not before been observed by me, though I am an old amateur. 'To be sure, for the last six years, I have always been, about the lime of blooming, absent at the Reichstag, and perhaps, therefore, have forgotten early single observations. It may not be possible to abtain a positive explanation. The dryness of the spring, perhaps the colour-sense of the bird, or even a more or less delicate mixture of the plant-sap may account for it-quien sabe !
Hamburg, May 12
W. VON FREEDEN

Editor of the Hansa

\section{Sound and Light}

I sHould like to learn if the following phenomenon is well known and alluded to in scientific writings. While lying awake a few mornings ago, with my eyelids closed, I was startled by a railway whistle. At the same instant I perceived a blaze of light on a dark ground seemingly a few yards off. I made inquiry of my wife (who is of a much more nervous temperament than I) if she had ever observed such a coincidence, and was informed that in her case it is not a very unfrequent occurrence. I likewise reported the circumstance to some scientific friends, but they had neither rearl nor heard of noise being the occasioning cause of sensation of colour.

While the pen is in my hand I may mention, in reference to Mr. Renshaw's communication (p. 530), that sparrows are in the habit of demolishing the flowers of my yellow crocuses.

Bushy Hill, Cambuslang

Henry Muirhead

\section{Cloud Colours}

A VEIN of thought is sometimes as a vein of the most fine gold, and observation is everything in meteorology as it is in geology, in which two difficult sciences we are much interested in this country, and of which your contributor is the unpretending student.

Now I first learned my lessons in weather science from the remarks of Admiral Fit2roy, the author of the Weather Book, which should be well known and read in this country. For years we have marked what an intimate correlation there is between the colour of the clouds and coming weather. Thus we have the cold dark blue and grey, and the reddish yellow masses of cloud as indicative of cold and snow, and we have the light bright grey with bright edges as accompanying or indicating hard frost. Then again we have the inky-coloured cloud, flying in shreds, as indicative of wind and rain, and also the mottled cloud of the same colour or thereabouts, as the sure indicative of rain. We have the sickly-looking green, the deep blue gloom, the muddy angry-looking red, and other such tints, as forecasts of storm, snow, rain, \&c. ; and frequently before 2 north-easter we have the grey bluish and whitish clouds setting from north-east, somewhat like the spread-out fingers of the hand. Our sunsets are often grand beyond my pen. The lavish wealth of crimson and gold is magnificent. It strikes us now to ask what relation chemistry and gases have with the cloud colours, I leave that 